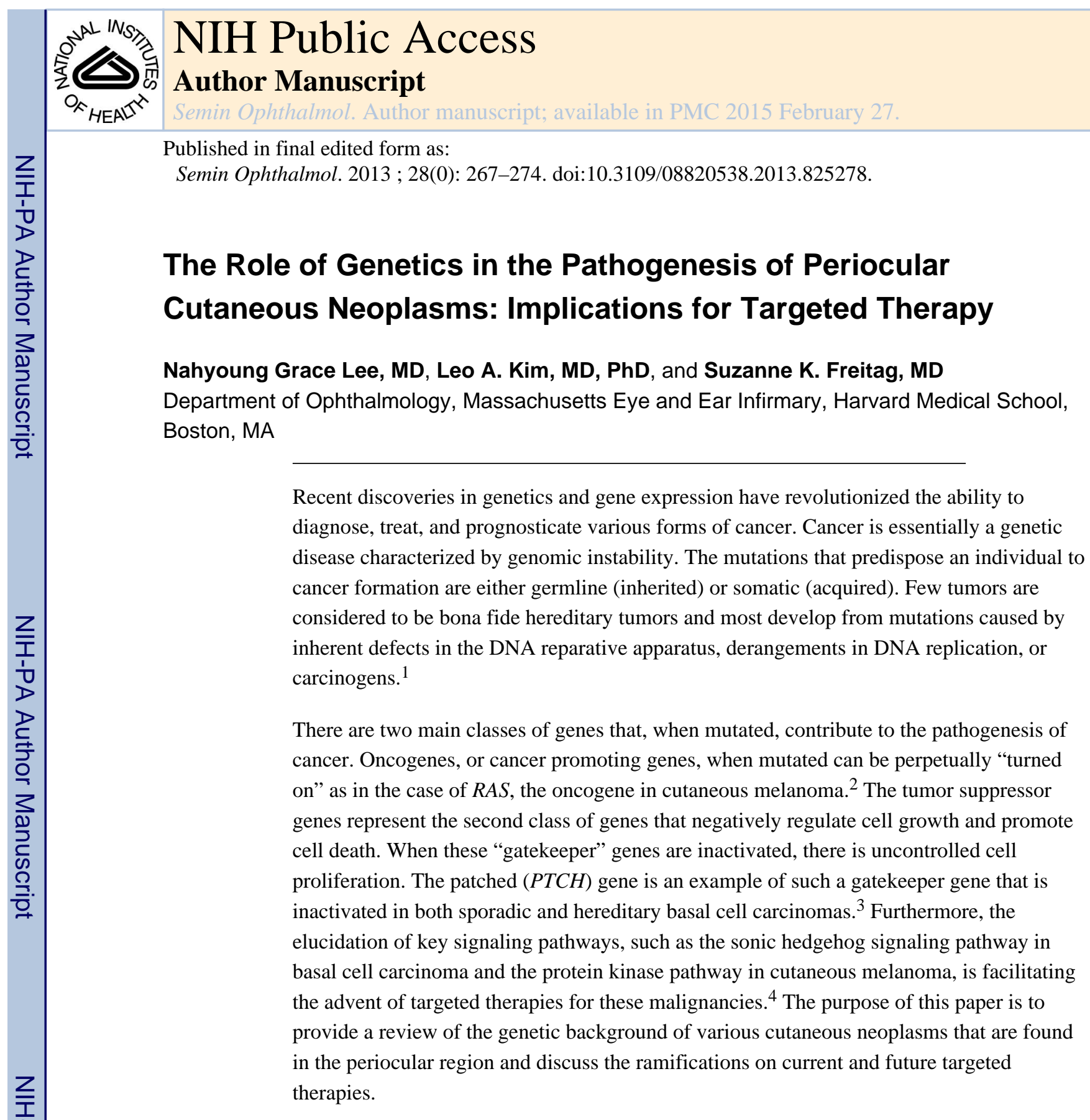

\title{
Basal Cell Carcinoma
}

Basal cell carcinoma (BCC) is the most common human malignancy, accounting for approximately $90 \%$ of eyelid cancers in the United States. ${ }^{5}$ Although many risk factors for BCC have been identified including fair skin type, ultraviolet (UV) exposure, immunosuppression, ionizing radiation, and advanced age, the underlying mechanism is genetic alteration. ${ }^{4}$

Corresponding Author: Nahyoung Grace Lee, MD, Massachusetts Eye and Ear Infirmary, 243 Charles Street, Boston, MA 02114, Grace_Lee@meei.harvard.edu.

None of the authors have any financial interests or disclosures. 


\section{Sonic Hedgehog (Shh)}

It has been known since 1996 that a mutation in the patched 1 gene (PTCH1) located at chromosome 9q22.3 was linked to basal cell nevus syndrome, or Gorlin Syndrome. ${ }^{6,7}$ $\mathrm{PTCH} 1$ is involved in the sonic hedgehog signaling pathway, which was first discovered in Drosophila melanogaster, and found to be critical to the proper formation of segments of the fruit fly during embryogenesis. ${ }^{8}$ This signaling pathway begins at the primary cilium, which is present on most cells during interphase. ${ }^{9}$ PTCH1, a 12-transmembrane domain protein, normally functions to block Shh signaling by antagonizing the activity of Smoothened (SMO), a seven domain transmembrane protein, preventing its migration into the cilium. ${ }^{9}$ The downstream events involving a family of zinc-finger transcription factors called GLI play a key role in mediating the Shh signal. ${ }^{8}$ If the tumor suppressive action of $\mathrm{PTCH} 1$ is inactivated, there is subsequent dysregulation of the Shh pathway with a resulting predisposition to developing BCC (Figure 1). The $\mathrm{PTCH}$ l gene mutation is also seen in up to $70 \%$ of sporadic cases of BCC. Basal cell carcinomas overexpress the transcription factors GLI1 and GLI2, which indicates that the Shh pathway is constitutively active in BCC. ${ }^{10}$ Aside from tumorigenesis, the Shh pathway activation is known to play a role in mammalian visual system development. Shh is expressed in the retinal ganglion cells and has been known to play a role in precursor cell proliferation, photoreceptor differentiation, and normal cellular organization in the rodent retina. ${ }^{11}$ Moreover, in patients with Gorlin syndrome, focal areas of dysplasia involving retinal cells in the outer nuclear layer have been reported. ${ }^{11}$

Vismodegib (GDC-0449), an oral inhibitor of the Hedgehog pathway which works by antagonizing SMO (Figure 1), was approved by the US Food and Drug Administration (FDA) in January 2012 for treatment of metastatic and locally advanced BCC. ${ }^{12}$ A multicenter phase 2 clinical trial of vismodegib was conducted on 104 patients from February 2009 through November 2010. Of the 33 patients that were enrolled with metastatic BCC, $30 \%$ were found to have a response. In 63 patients with locally advanced basal cell carcinoma, the response rate was $43 \%$, with complete responses in 13 patients $(21 \%)$. Locally advanced BCC was defined as at least 1 lesion $10 \mathrm{~mm}$ or more in longest dimension and considered unresectable for one of the following reasons: the patient had recurrence after 2 or more surgical procedures or surgery was expected to result in substantial morbidity or deformity. ${ }^{13}$ Disease progression was noted in $18 \%$ of patients with metastatic disease. An additional phase 2 trial was conducted in 41 patients with Gorlin syndrome. Vismodegib was associated with a decrease in the number of new and existing surgically eligible BCCs compared to placebo. Surgically eligible BCCs were defined as BCCs with a diameter of $3 \mathrm{~mm}$ or greater on the nose or periorbital skin, $5 \mathrm{~mm}$ or greater elsewhere on the face, or $9 \mathrm{~mm}$ or greater on the trunk or limbs. The effect of this medication against BCC was associated with a decrease in hedgehog signaling with a $90 \%$ decrease in GLI1 messenger RNA in biopsy specimens treated for 1 month. Histologic examination revealed no detectable BCC in biopsies from clinically regressed areas in $83 \%$ of samples. ${ }^{14}$ The tumors were observed to recur when the medication was stopped. ${ }^{14}$

The adverse effects profile of vismodegib included toxicities considered to be grade 1 or 2 (mild to moderate). Despite the low-grade toxicities, adherence to the anticancer agent was 
compromised by the side effects and the discontinuation rates from loss of taste and muscle cramps were $12 \%$ and $27 \%$ respectively. Serious adverse events were reported in $25 \%$ including death in seven patients. ${ }^{13}$ These seven patients were thought to have coexisting conditions at baseline and the relationship between the study drug and the deaths is unknown. ${ }^{13}$

Cyclopamine is a naturally occurring sterol alkaloid derived from the Veratrum californicum plant, which was postulated to inhibit the Shh signaling pathway when cyclopia was reported in offspring of pregnant sheep that ingested small quantities of the plant. Its main mechanism of action occurs by binding and inactivating SMO (Figure 1). Cyclopamine was topically found to be successful in advanced BCC in a phase 1 clinical trial. ${ }^{4}$

Other SMO inhibitors have been investigated which include an antifungal, itraconazole, and arsenic trioxide. These agents inhibit SMO and GLI1 in a distinct mechanism than the other Smoothened antagonists, thus conferring inhibition in drug-resistant SMO mutants (Figure 1). ${ }^{15}$

Mutations in the gene TP53, which encodes the protein P53, occur in a wide variety of tumor types and disruption of this pathway occurs in most human cancers. P53 is known as the "guardian of the genome"16 and functions to sense genotoxic injury and arrest cell division allowing DNA repair prior to replication. It also induces apoptosis in cases of extensive DNA damage to eliminate defective and potentially malignant cells. ${ }^{16}$ The germ line mutation of TP53, Li-Fraumeni syndrome, does not predispose the patient to BCC, but may be a secondary event occurring after tumor initiation. ${ }^{16}$ In fact, mutations of TP53 are actually found in $44-100 \%$ of BCC tumors themselves rather than in the germ line.

Moreover, patients using sunscreen had significantly less TP53 mutations in their tumors compared with those not using sunscreen, further suggesting that TP53 mutation is a secondary event and not responsible primarly for carcinogenesis. ${ }^{10}$

Melanocortin-1 receptor variants. The melanocortin-1 receptor (MC1R) is a key protein regulating skin and hair pigmentation. Human MC1R variants have been found in a large proportion of white individuals. The red hair color variant alleles contribute to fair skin, freckling, and poor tanning response to UV, which in turn leads to decreased capacity to produce eumelanin and reduced skin photoprotectivity. ${ }^{17}$ Carriers of any two variant alleles are at increased risk of developing both nodular BCC and superficial BCC. Thus, MC1R variants may be an independent risk factor for the development of BCC. There is ongoing research to see if there is potential merit in pursuing MC1R agonists for skin cancer prevention. There have been no clinical trials as of yet. ${ }^{18}$

\section{Squamous Cell Carcinoma}

Cutaneous squamous cell carcinoma (SCC) is the second most common eyelid malignancy accounting for 5\% of all eyelid malignancies in the United States. ${ }^{19}$ Unlike BCC, which has no precursor lesion, SCC can develop from actinic keratosis. Squamous lesions are thought 
to occur on chronically sun-exposed sites, suggesting that UV radiation is the leading environmental risk factor.

The development of SCC is thought to involve anti-apoptotic and cell proliferative pathways including TP53, RAS, and $p 16 / C D K N 2 A{ }^{1}$

TP53

Inactivation of this tumor suppressive gene is reported to play a crucial role in development of actinic keratosis and SCC. Brash et $\mathrm{al}^{20}$ found that $14(58 \%)$ of 24 invasive SCCs of the skin contain mutations in TP53. Inactivation of p53 occurs in precancerous lesions, suggesting that early loss of p53 function contributes to later malignant degeneration. Moreover, UV irradiation in mice with deficient p53 activity leads to decreased apoptotic ability, likely leading to an inability to abort precancerous cells. ${ }^{21}$ Similar to BCC, the germline mutation in TP53 in Li-Fraumeni syndrome does not increase the risk for SCC.

\section{RAS}

Mutations that activate the oncogene $R A S$ are among the most common oncogenic lesions in human cancer. The reported frequency of $R A S$ mutations in SCC ranges from approximately $10 \%$ to nearly $50 \% .^{22}$

\section{EGFR}

Epidermal growth factor receptor is another common oncogene that is implicated in SCC of the head and neck. ${ }^{23}$ The results of EGFR activation in keratinocytes are increased survival and resistance to apoptosis (Figure 2). Overexpression of EGFR has been implicated in cutaneous carcinoma of the head and neck, glioma, breast carcinoma, bladder cancer, and non-small-cell lung carcinoma. ${ }^{24}$ Studies have shown that the degree of overexpression of EGFR correlates with the aggressiveness of cutaneous SCC. Strong EGFR overexpression was seen in $79 \%$ of 64 patients that had metastases compared with $36 \%$ of cases without metastases. ${ }^{25}$ Furthermore, multivariate analysis by the same group of researchers found that EGFR expression was an independent predictor of metastasis. ${ }^{25}$ Therefore, inhibitors of EGFR have been investigated for potential treatment of various cancers.

Gefitinib, a tyrosine kinase inhibitor, was used for treatment of solid tumors including nonsmall-cell carcinoma starting in 2003. It works by selectively inhibiting EGF-stimulated tumor cell growth and has been shown to block autophosphorylation in tumor cell lines in vitro, which in turn, prevents the remodeling of the cytoskeleton, proliferation, and induces a more differentiated phenotype (Figure 2). ${ }^{26}$ A study was conducted on 22 patients with recurrent or aggressive SCC, defined as lesions that were $2 \mathrm{~cm}$ or greater, invaded deep tissue, or were associated with perineural invasion and/or metastasis to lymph nodes. Neoadjuvant treatment with oral gefitinib provided an overall response rate of $45.5 \%$ without treatment-related deaths. Fifty-nine percent of patients (13/22) experienced grades 2 and 3 toxicities including diarrhea, fatigue, and acneiform rash. ${ }^{27}$

Erlotinib is also a tyrosine kinase inhibitor that inhibits tumor cell proliferation and autophosphorylation (Figure 2). Although it was approved by the US FDA in 2004 for 
treatment of locally advanced or metastatic non-small-cell lung carcinoma and pancreatic cancer, clinical trials of erlotinib for cutaneous SCC have not yet been completed. ${ }^{28}$ The most prominent side effects were rash and diarrhea. There have been numerous case reports of treatment of cutaneous squamous cell carcinoma with erlotinib. In a case of a 90-year-old woman with invasive SCC of the orbit, which would have required exenteration, parotidectomy, and neck dissection followed by free flap reconstruction and adjuvant radiation therapy, a decision was made to treat her non-invasively, because of her age and history of significant coronary artery disease. After three months of treatment, she had marked improvement in her clinical examination including visual acuity as well as both proptosis and ocular motility, although residual tumor remained. ${ }^{29}$

Cetuximab is a monoclonal antibody to EGFR, which has greater specificity than the previously mentioned tyrosine kinase inhibitors but requires intravenous infusion (Figure 2) ${ }^{30}$ Currently, cetuximab is approved by the US Food and Drug Administration for use in certain types of head and neck cancer in conjunction with radiation therapy. A phase 2 clinical trial of cetuximab as a single-agent therapy for cutaneous SCC included 36 patients with surgically unresectable or metastatic SCC. ${ }^{30}$ Seventy-two percent of patients had lesions with high EGFR expression. Partial or complete response was seen in $69 \%$ of 36 patients at a dosage of $400 \mathrm{mg} / \mathrm{m}^{2}$ loading dose followed by weekly infusions of $250 \mathrm{mg} / \mathrm{m}^{2}$ for at least 6 weeks. ${ }^{30}$ Interestingly, tumor EGFR expression levels were not associated with treatment efficacy. ${ }^{30}$ Seven patients died during the treatment, but were considered to be related to disease progression or general conditions. The most frequent adverse effect was an acne-like rash occurring in $87 \%$ of the patients. ${ }^{30}$

\section{Sebaceous carcinoma}

Sebaceous carcinoma comprises 5\% of all eyelid malignancies in the United States and approximately $40 \%$ of all sebaceous gland carcinomas arise in the ocular adnexal skin. ${ }^{31}$ Muir-Torre syndrome is an autosomal dominant disorder characterized by sebaceous skin tumors, with or without keratoacanthomas, and visceral malignancies. It is considered to be a variant of hereditary nonpolyposis colorectal cancer syndrome (HNPCC). Cutaneous manifestations of Muir-Torre syndrome can occur before, concurrent with, or after the diagnosis of a visceral malignancy. ${ }^{32}$ Seventy percent of patients with Muir-Torre syndrome are reported to have a germline mutation in one allele of the mismatch repair genes, which encode mismatch repair proteins, essential for the maintenance of genomic integrity. Acquisition of a somatic "second-hit" mutation in a second allele leads to defective mismatch repair function and subsequent accumulation of genetically unstable cells. ${ }^{32}$ The strength of the association of sebaceous carcinoma with Muir-Torre syndrome is debated. Most studies agree that periocular sebaceous carcinoma is rarely associated with Muir-Torre syndrome. ${ }^{33}$

TP53

$67 \%$ of eyelid sebaceous carcinomas were detected to have point mutations in TP53 in a study by Kiyosaki et al. ${ }^{34}$ In other cancers, the TP53 mutation status has been reported to be a useful prognostic marker or predictor of therapy response. Furthermore, in SCC of the eye and adnexa and BCC, TP53 mutation analysis has implicated UV radiation as the major 
carcinogen involved. However, Kiyosaki et al also found that the point mutations detected in TP53 in 10 out of 15 cases were not induced by UV stimulus as in SCC and BCC. ${ }^{34} \mathrm{UV}$ related mutations in TP53 occur at dipyrimidine sites in $92 \%$ of skin tumors. In contrast, internal malignancies contain this particular mutation in TP53 only $61 \%$ of the time, which was consistent with what Kiyosaki et al reported in their sebaceous carcinomas of the eyelid. This suggests that sebaceous carincomas of the eyelid contain mutations that are distinct from those of other skin cancers and are potentially not stimulated by UV exposure. ${ }^{34}$ Moreover, the downregulation of $p 21$ (transcriptional target of p53) expression was associated with lymph node metastases and was thought to be a potential prognostic marker of nodal metastases in sebaceous carcinoma of the eyelid. ${ }^{34}$

\section{Sonic Hedgehog and Wnt Signaling Pathways}

Activation or dysregulation of the Shh and Wnt signaling pathways is suggested to lead to the development of many human malignancies, including BCC. Kim et al. studied 37 cases of eyelid sebaceous gland carcinoma wherein 8 patients showed lymph node or distant metastasis. The group with metastasis showed higher expression levels of Shh and Wnt than did the group without metastasis, implying that activation of the Shh and Wnt signaling pathway is associated with aggressive behavior of the tumor. ${ }^{35}$

One gene expression profiling study showed dysregulation of the MAPK and JAK/STAT pathways in meibomian gland carcinomas through microarray analysis. Clusters of genes on chromosomes 1,12 , and 19 were also found to be dysregulated. ${ }^{36}$ This study may be a precursor to future identification of specific markers or therapeutic targets in sebaceous carcinoma of the eyelid.

\section{Cutaneous Malignant Melanoma}

Cutaneous malignant melanoma develops from a malignant proliferation of melanocytes and accounts for $5 \%$ of all malignant cutaneous tumors and $1 \%$ of all eyelid malignancies. These lesions can arise de novo or from pre-existing nevi. ${ }^{37} \mathrm{~A}$ family history of melanoma is elucidated in $10 \%$ of melanoma patients and increases the risk of melanoma by two-fold. ${ }^{38}$ On a molecular level, activation of proliferative kinase signaling pathways is thought to be responsible for the transformation of a normal melanocyte into melanoma. These signaling pathways involve $B R A F, N R A S$, and KIT oncogenes. ${ }^{39}$ Not only is there activation of these proliferative kinase signaling pathways, but there is also additional dysregulation of apoptotic pathways involving tumor suppressor genes CDKN2A, TP53, and PTEN for the development of melanoma. ${ }^{39}$ Genomic instability occurs predominantly at the chromosomal level in melanoma. Over $95 \%$ of melanomas show multiple gains and losses of chromosomal portions, most frequently involving chromosomes 1, 6, 7, 9, 10,11, 17, and $20 .{ }^{39}$

\section{Cyclin-dependent kinase N2A (CDKN2A)}

Linkage analysis studies of families with an increased occurrence of melanoma led to putative loci on chromosome 9p21. Within the 9p21 region, the CDKN2A gene was established as a high-risk susceptibility locus in melanoma. ${ }^{40} C D K N 2 A$ inhibits the activity 
of cyclin-dependent kinase 4 (CDK4) complex, whose function is to drive cell cycle progression by phosphorylating RB protein (Figure 3). Several studies have estimated the risk of developing cutaneous melanoma among $C D K N 2 A$ mutation carriers. In familial cases, the overall penetrance is $30 \%$ by age 50 and $67 \%$ by age 80 . Among sporadic CDKN2A carriers, the risk is $14 \%$ by age 50 and $28 \%$ by age $80 .{ }^{41}$

RB1

Carriers of the $R B 1$ germline mutation have a fourfold to 80 -fold elevated risk to develop melanoma. Unlike in sarcomas, the incidence of melanomas does not correlate with radiotherapy use, which is likely due to loss of heterozygosity $(\mathrm{LOH})$ for the $R B 1$ allele. This demonstrates that there is an intricate linkage between the CDKN2A/CDK/RB pathways of tumor suppression in humans. ${ }^{42}$

\section{MC1R}

$M C 1 R$ variants are considered to be low to moderate risk melanoma loci. A meta-analysis found that presence of $M C 1 R$ variants is associated with 1.5-2.5 fold odds ratio of developing melanoma; however, the risk appears to be pigmentation-independent, suggesting that $M C 1 R$ has some cancer effects independent of pigmentation (Figure 3). ${ }^{42}$

Receptor tyrosine kinase (RTK). The $c$-KIT gene encodes the RTK for stem cell factor $(S C F)$, which transmits activation signals via the RAS-GTPase and in turn leads to sequential activation of $R A F, M E K$, and $E R K$, which leads ultimately to phosphorylation of key transcription factors and proteins involved in cell proliferation and cell cycle regulation (Figure 3). Pharmacologic targeting of KIT-mutated melanomas took place in two phase II trials of imatinib. In one trial, 28 patients with metastatic KIT-altered melanomas were treated with two complete responses and two partial responses. ${ }^{43}$ In the second trial, 43 patients with metastatic melanomas were treated with imatinib revealing only partial responses in $23.3 \%$ and disease stabilization in $30.2 \%$ and disease progression in $46.5 \%{ }^{44}$ Thus, only modest effects were seen with imatinib; however, other RTK inhibitors (sunitinib, nilotinib, and dasatinib) are currently being tested for efficacy (Figure 3). ${ }^{42}$

\section{Epidermal growth factor receptor (EGFR)}

Unlike squamous cell carcinoma, neither activating EGFR mutations nor focal $E G F R$ amplifications have been observed in melanoma. Most studies linking EGFR activation to melanoma biology have relied on protein expression or activation studies. Based on in vitro studies, it was thought that pharmacological blockade of EGFR with gefitinib could suppress growth in melanoma cell lines (Figure 3) ${ }^{45}$ Phase II trials of EGFR inhibitor gefitinib in 46 metastatic melanoma patients revealed disappointing results. The median progression-free survival was only 1.4 months and median overall survival was 9.7 months. ${ }^{46}$

\section{BRAF}

$B R A F$ activation is thought to be at the heart of melanomagenesis. This gene encodes a protein belonging to a family of protein kinases which plays a role in regulating the MAP kinase/ERKs signaling pathway (Figure 3). The MAP kinase pathway affects cell division, differentiation and secretion. Other than oncologic conditions, $B R A F$ mutations have been 
associated with cardiofaciocutaneous syndrome. $B R A F$ mutations have been observed in approximately $50 \%$ of melanomas and to a lesser extent in other cancers. ${ }^{47}$ These mutations also occur at high frequencies in melanocytic nevi $(>80 \%) .{ }^{48}$ The exact relationship between $B R A F$ mutations and sun exposure is still unclear. Yet, $B R A F$ mutations are much more common in melanomas arising on sun-exposed lesions than in acral melanomas. ${ }^{49}$ Strikingly, BRAF mutations are absent in uveal melanoma. ${ }^{49}$ The data suggests that BRAF mutations are important in induction of proliferation and senescence of melanocytic nevi and in melanoma progression, but are not the sole drivers of oncogenic melanocytic transformation. ${ }^{50}$ Selective $B R A F$ inhibitors have been approved by the FDA. For example, vemurafenib, a selective inhibitor of mutated BRAF has shown clinical efficacy in the metastatic setting (Figure 3). ${ }^{51}$ The rates of overall survival in a phase III study with vemurafenib were $84 \%(\mathrm{~N}=336) .{ }^{51}$ This medication was eventually approved by the FDA in 2011.

MEK

Recent research has revealed that $M E K$ mutations are present in melanoma. $M E K$ inhibition was investigated prior to the advent of selective $R A F$ inhibitors and was found to have exquisite potency against BRAF melanomas. AZD6244, a MEK inhibitor, has shown clinical promise both as single agents and in combination with $R A F$ inhibitors (Figure 3). 52

\section{Merkel Cell Carcinoma}

Merkel Cell Carcinoma (MCC) is a highly aggressive neuroendocrine tumor that is very rare, yet twice as lethal as melanoma with a greater than $33 \%$ mortality rate. ${ }^{53}$ It was once thought that light skin pigmentation and sun exposure were risk factors for the development of MCC; however, the recent identification of Merkel cell polyomavirus (MCV) has dramatically changed our understanding of the pathophysiology of this malignancy. ${ }^{54}$ Immunodeficiency and immunosuppression also may play a role in the pathogenesis of MCC with increased rates in solid organ transplant recipients and in individuals with HIV and AIDS. ${ }^{55}$

Merkel cell polyomavirus (MCV). The MCV encodes two major families of genes: 1) Large $\mathrm{T}$ antigen (LT) an Small T antigen (ST) and 2) late genes (viral proteins). The MCV LT antigen sequences harbor mutations, which prematurely truncate the protein thereby eliminating the helicase function of the LT. The hsc70 and RB binding motif are left intact. The truncation does not appear to affect the RB binding domain. ${ }^{56}$ The high degree of association of MCV with MCC is beginning to be exploited in diagnostics as well as prognostication. One study has shown that patients with MCV-positive tumors had 5-year survival rates of $45 \%$ as compared to $13 \%$ 5-year survival rates in cases with MCV-negative MCC. ${ }^{57}$ Finally, viral proteins in tumor cells are also promising targets for future therapies. For example, immunization with the DNA MCV vaccine was recently shown to be successful in reducing the tumor volume and in prolonging survival in a murine MCC model. ${ }^{58}$

Recent advances and improvement in our comprehension of the pathogenesis of these periocular cutaneous malignancies have translated into great strides in diagnosis and 
management of patients. Molecular genetics have opened doors to targeted therapy for many of these neoplasms where resection and radiation were the only options in the past. Now, there are ongoing clinical trials of treatments that may bring promise to patients in whom resection is not an option or would cause significant morbidity. This may eventually lead to primary medical rather than surgical management of many cutaneous malignancies.

\section{References}

1. Tsao H. Genetics of nonmelanoma skin cancer. Arch Dermatol. 2001; 137:1486-1492. [PubMed: 11708952]

2. Van Elsas A, Zerp SF, vander Flier S, et al. Relevance of ultraviolet-induced N-ras oncogene point mutations in development of primary human cutaneous melanoma. Am J Pathol. 1996; 149:883893. [PubMed: 8780392]

3. Aszterbaum M, Rothman A, Johnson RL, et al. Identification of mutations in the human PATCHED gene in sporadic basal cell carcinomas and in patients with the basal cell nevus syndrome. J Invest Dermatol. 1998; 110:885-888. [PubMed: 9620294]

4. Iwasaki JK, Srivastava D, Moy RL, Lin HJ, Kouba DJ. The molecular genetics underlying basal cell carcinoma pathogenesis and links to targeted therapeutics. J Am Acad Dermatol. 2010; 66:e167e178. [PubMed: 20800318]

5. Prabhakaran VC, Gupta A, Juilgol SC, Selva D. Basal cell carcinoma of the eyelids. Compr Ophthalmol Update. 2007; 8:1-14. [PubMed: 17394754]

6. Hahn H, Wicking C, Zaphiropoulous PG, et al. Mutations of the human homolog of Drosophila patched in the nevoid basal cell carcinoma syndrome. Cell. 1996; 85:841-51. [PubMed: 8681379]

7. Johnson RL, Rothman AL, Xie J, et al. Human homolog of patched, a candidate gene for the basal cell nevus syndrome. Science. 1996; 272:1668-71. [PubMed: 8658145]

8. Tang JY. Elucidating the role of molecular signaling pathways in the tumorigenesis of Basal Cell Carcinoma. Semin Cutan Med Surg. 2011; 30:S6-S9. [PubMed: 22177103]

9. Caro I, Low JA. The role of the hedgehog signaling pathway in the development of basal cell carcinoma and opportunities for treatment. Clin Cancer Res. 2010; 16:3335-3359. [PubMed: 20439455]

10. De Zwaan SE, Haass NK. Genetics of basal cell carcinoma. Australas J Dermatol. 2010; 51:81-94. [PubMed: 20546211]

11. Black GCM, Mazerolle CJ, Wang Y, Campsall KD, Petrin D, et al. Abnormalities of the vitreoretinal interface caused by dysregulated Hedgehog signaling during retinal development. Human Molecular Genetics. 2003; 12:3269-3276. [PubMed: 14570707]

12. US Food and Drug Administration. FDA approves new treatment for most common type of skin cancer [News Release]. www.fda.gov/NewsEvents/Newsroom/PressAnnouncements/ ucm289545.htm

13. Sekulic A, Migden MR, Oro AE, et al. Efficacy and safety of vismodegib in advanced basal-cell carcinoma. N Engl J Med. 2012; 366:2171-9. [PubMed: 22670903]

14. Tang JY, Mackay-Wiggan JM, Aszterbaum M, et al. Inhibiting the hedgehog pathway in patients with the basal-cell nevus syndrome. N Engl J Med. 2012; 366:2180-8. [PubMed: 22670904]

15. Kim J, Aftab BT, Tang JY, Kim D, Lee AH, et al. Itraconazole and arsenic trioxide inhibit Hedgehog pathway activation and tumor growth associated with acquired resistance to smoothened antagonists. Cancer Cell. 2013; 23:23-34. [PubMed: 23291299]

16. Lane DP. Cancer. P53, guardian of the genome. Nature. 1992; 358:15-16. [PubMed: 1614522]

17. Valverde P, Healy E, Jackson I, et al. Variants of the melanocyte-stimulating hormone receptor gene are associated with red hair and fair skin in humans. Nat Genet. 1995; 11:328-30. [PubMed: 7581459]

18. Abdel-Malek ZA. Development of a-melanocortin analogs for melanoma prevention and targeting. Adv Exp Med Biol. 2010; 681:126-32. [PubMed: 21222265] 
19. Nindl I, Rosl F. Molecular pathogenesis of squamous cell carcinoma. Cancer Treat Res. 2009; 146:205-211. [PubMed: 19415205]

20. Brash DE, Rudoph JA, Simon JA, et al. A role for sunlight in skin cancer: UV-induced p53 mutations in squamous cell carcinoma. Proc Natl Acad Sci U S A. 1991; 88:10124-10128. [PubMed: 1946433]

21. Ziegler A, Jonason AS, Leffell DJ, et al. Sunburn and p53 in the onset of skin cancer. Nature. 1994; 372:773-776. [PubMed: 7997263]

22. Spencer JM, Kahn SM, Jiang W, et al. Activated ras genes occur in human actinic keratoses, premalignant precursors to squamous cell carcinomas. Arch Dermatol. 1995; 131:796-800. [PubMed: 7611795]

23. Hunt JL, Barnes L, Lewis JS Jr, et al. Molecular diagnostic alterations in squamous cell carcinoma of the head and neck and potential diagnostic applications. Eur Arch Otorhinolaryngol. 2013 Mar 7. Epub ahead of print.

24. Uribe P, Gonzalez S. Epidermal growth factor receptor (EGFR) and squamous cell carcinoma of the skin: molecular bases for EGFR-targeted therapy. Pathol Res Pract. 2011; 207:337-42. [PubMed: 21531084]

25. Ch'ng S, Low I, Ng D, et al. Epidermal growth factor receptor: a novel biomarker for aggressive head and neck cutaneous squamous cell carcinoma. Hum Pathol. 2008; 39:344-9. [PubMed: 18045646]

26. Wakeling AE, Guy SP, Woodburn JR, et al. ZD1839 (Iressa): an orally active inhibitor of epidermal growth factor signaling with potential for cancer therapy. Cancer Res. 2002; 62:5749_ 54. [PubMed: 12384534]

27. Lewis CM, Glisson BS, Feng L, et al. A phase II study of gefitinib for aggressive cutaneous squamous cell carcinoma of the head and neck. Clin Cancer Res. 2012; 18:1435-46. [PubMed: 22261807]

28. Moyer JD, Barbacci EG, Iwata KK, et al. Induction of apoptosis and cell cycle arrest by CP-358,774, an inhibitor of epidermal growth factor receptor tyrosine kinase. Cancer Res. 1997; 57:4838-48. [PubMed: 9354447]

29. Yin VT, Pfeiffer ML, Esmaeli B. Targeted Therapy for orbital and periocular basal cell carcinoma and squamous cell carcinoma. Ophthal Plast Reconstr Surg. 2013; 29:1-6.

30. Maubec E, Petrow P, Scheer-Senyarich I, et al. Phase II study of cetuximab as first-line single-drug therapy in patients with unresectable squamous cell carcinoma of the skin. J Clin Oncol. 2011; 29:3419-26. [PubMed: 21810686]

31. Shields JA, Shields CL. Sebaceous adenocarcinoma of the eyelid. Int Ophthalmol Clin. 2009; 49:45-61. [PubMed: 20348857]

32. Abbas O, Mahalingam M. Cutaneous sebaceous neoplasms as markers of Muir-Torre syndrome: a diagnostic algorithm. J Cutan Pathol. 2009; 36:613-619. [PubMed: 19515040]

33. Gaskin BJ, Fernando BS, Sullivan CA, et al. The significance of DNA mismatch repair genes in the diagnosis and management of periocular sebaceous cell carcinoma and Muir-Torre syndrome. Br J Ophthalmol. 2011; 95:1686-1690. [PubMed: 21979897]

34. Kiyosaki K, Nakada C, Hijiya N, et al. Analysis of p53 mutations and the expression of p53 and p21WAFI/CIP1 protein in 15 cases of sebaceous carcinoma of the eyelid. Invest Ophthalmol Vis Sci. 2010; 51:7-11. [PubMed: 19628749]

35. Kim N, Kim JE, Choung HK, et al. Expression of Shh and Wnt signaling pathway proteins in eyelid sebaceous gland carcinoma: clinicopathologic study. Invest Ophthalmol Vis Sci. 2013; 54:370-377. [PubMed: 23249701]

36. Kumar A, Dorairaj SK, Prabhakaran VC, et al. Identification of genes assocated with tumorigenesis of meibomian cell carcinoma by microarray analysis. Genomics. 2007; 90:559-566. [PubMed: 17889501]

37. Sanchez R, Ivan D, Esmaeli B. Eyelid and periorbital cutaneous malignant melanoma. Int Ophthalmol Clin. 2009; 49:25-43. [PubMed: 20348856]

38. Gandini S, Sera F, Cattaruzza MS, et al. Meta-analysis of risk factors for cutaneous melanoma: III. Family history, actinic damage and phenotypic factors. Eur J Cancer. 2005; 41:2040-2059. [PubMed: 16125929] 
39. Takata M, Murata H, Saida T. Molecular pathogenesis of malignant melanoma: a different perspective from the studies of melanocytic nevus and acral melanoma. Pigment Cell Melanoma Res. 2010; 23:64-71. [PubMed: 19788535]

40. Hussussian CJ, Struewing JP, Goldstein AM, et al. Germline p16 mutations in familial melanoma. Nat Genet. 1994; 8:15-21. [PubMed: 7987387]

41. Begg CB, Orlow I, Hummer AJ, et al. Lifetime risk of melanoma in CDKN2A mutation carriers in a population-based sample. J Natl Cancer Inst. 2005; 97:1507-1515. [PubMed: 16234564]

42. Tsao H, Chin L, Garraway LA, et al. Melanoma: from mutations to medicine. Genes Dev. 2012; 26:1131-1155. [PubMed: 22661227]

43. Carvajal RD, Antonescu CR, Wolchok JD, et al. KIT as a therapeutic target in metastatic melanoma. JAMA. 2011; 305:2327-2334. [PubMed: 21642685]

44. Guo J, Si L, Kong Y, Flaherty KT, et al. Phase II, open-label, single-arm trial of imatinib mesylate in patients with metastatic melanoma harboring c-Kit mutation or amplification. J Clin Oncol. 2011; 29:2904-2909. [PubMed: 21690468]

45. Boone B, Jacobs K, Ferdinande L. EGFR in melanoma: Clinical significance and potential therapeutic target. J Cutan Pathol. 2011; 38:492-502. [PubMed: 21352258]

46. Patel SP, Kim KB, Papadopoulos NE, et al. A phase II study of gefitinib in patients with metastatic melanoma. Melanoma Res. 2011; 21:357-363. [PubMed: 21738104]

47. Maldonado JL, Fridlyand J, Patel H, et al. Determinants of BRAF mutations in primary melanomas. J Natl Cancer Inst. 2003; 95:1878-1890. [PubMed: 14679157]

48. Pollock PM, Harper UL, Hansen KS, et al. High frequency of BRAF mutations in nevi. Nat Genet. 2003; 33:19-20. [PubMed: 12447372]

49. Cohen Y, Goldenberg-Cohen N, Parrella P, et al. Lack of BRAF mutation in primary uveal melanoma. Invest Ophthalmol Vis Sci. 2003; 44:2876-2878. [PubMed: 12824225]

50. Palmieri G, Capone M, Ascierto ML, et al. Main roads to melanoma. J Transl Med. 2009; 14:86. [PubMed: 19828018]

51. Flaherty K, Puzanov I, Sosman J, et al. Phase I study of PLX4032: Proof of concept for V600E BRAF mutation as a therapeutic target in human cancer. J Clin Oncol. 2009; 27:15s.

52. Solit DB, Garraway LA, Pratilas CA, et al. BRAF mutation predicts sensitivity to MEK inhibition. Nature. 2006; 439:358-362. [PubMed: 16273091]

53. Houben R, Schrama D, Becker JC. Molecular pathogenesis of Merkel cell carcinoma. Exp Dermatol. 2009; 18:193-198. [PubMed: 19400830]

54. Feng H, Shuda M, Chang Y, Moor PS. Clonal integration of a polyomavirus in human Merkel cell carcinoma. Science. 2008; 319:1096-10100. [PubMed: 18202256]

55. Penn I, First MR. Merkel's cell carcinoma in organ recipients: report of 41 cases. Transplantation. 199; 68:1717-21. [PubMed: 10609948]

56. Shuda M, Feng H, Kwun HG, et al. T antigen mutations are a human tumor-specific signature for Merkel cell polyomavirus. Proc Natl Acad Sci U S A. 2008; 105:16272-7. [PubMed: 18812503]

57. Sihto H, Kukko H, Koljonen V, et al. Clinical factors associated with Merkel cell polyomavirus infection in Merkel cell carcinoma. J Natl Cancer Inst. 2009; 101:938-945. [PubMed: 19535775]

58. Zeng Q, Gomez BP, Viscidi RP, et al. Development of a DNA vaccine targeting Merkel cell polyomavirus. Vaccine. 2012; 30:1322-1329. [PubMed: 22210138] 


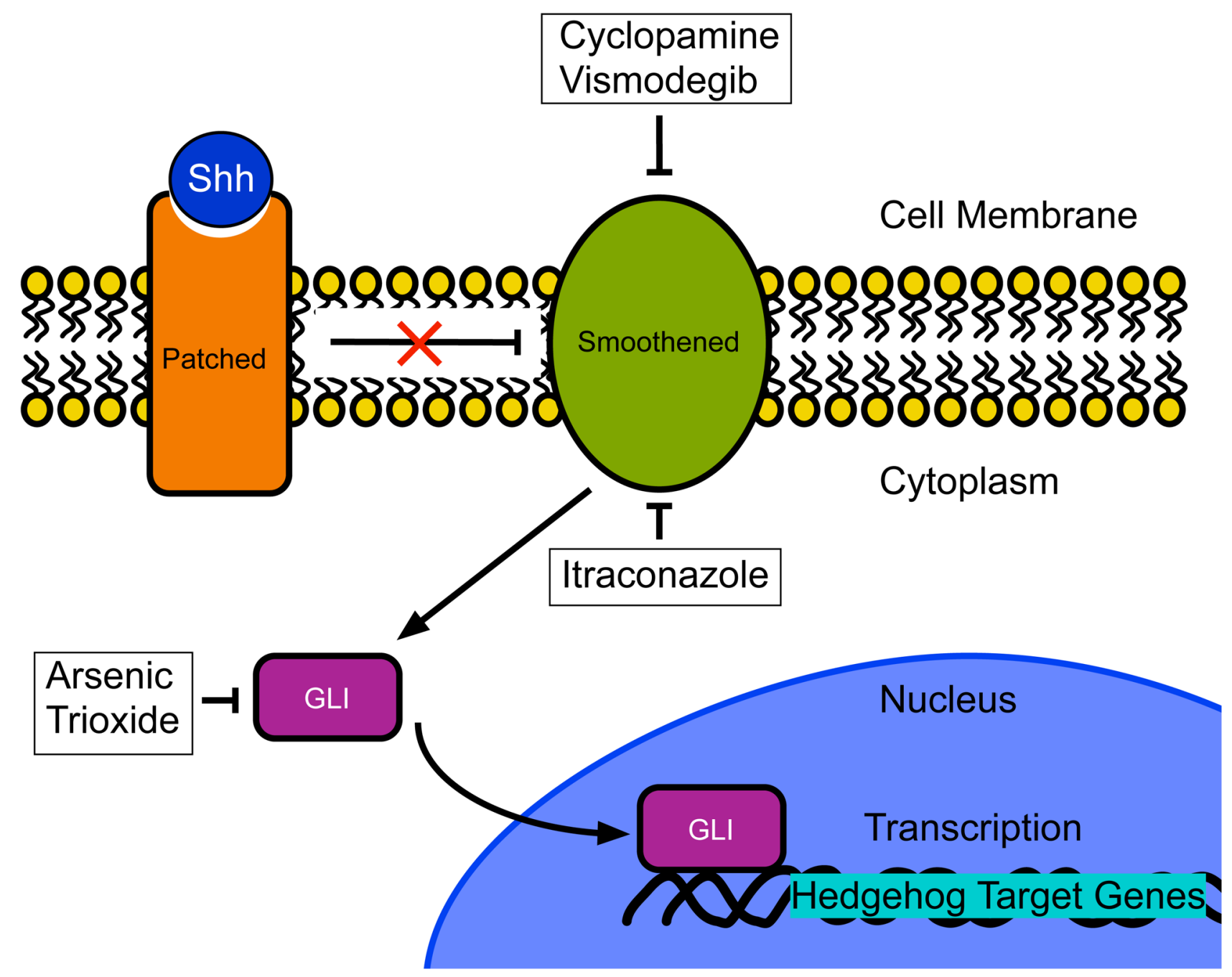

Figure 1.

Sonic hedgehog pathway. In the absence of ligand, the Sonic hedgehog (Shh) receptor, patched (PTCH) inhibits signaling through inhibition of the transmembrane protein Smoothened (SMO). Ligand occupation of PTCH inactivates the receptor and allows activation of SMO that, in turn, results in the induction of GLI transcription factors. Vismodegib, cyclopamine, and itraconazole are inhibitors of SMO whereas arsenic trioxide acts by inhibiting GLI. 


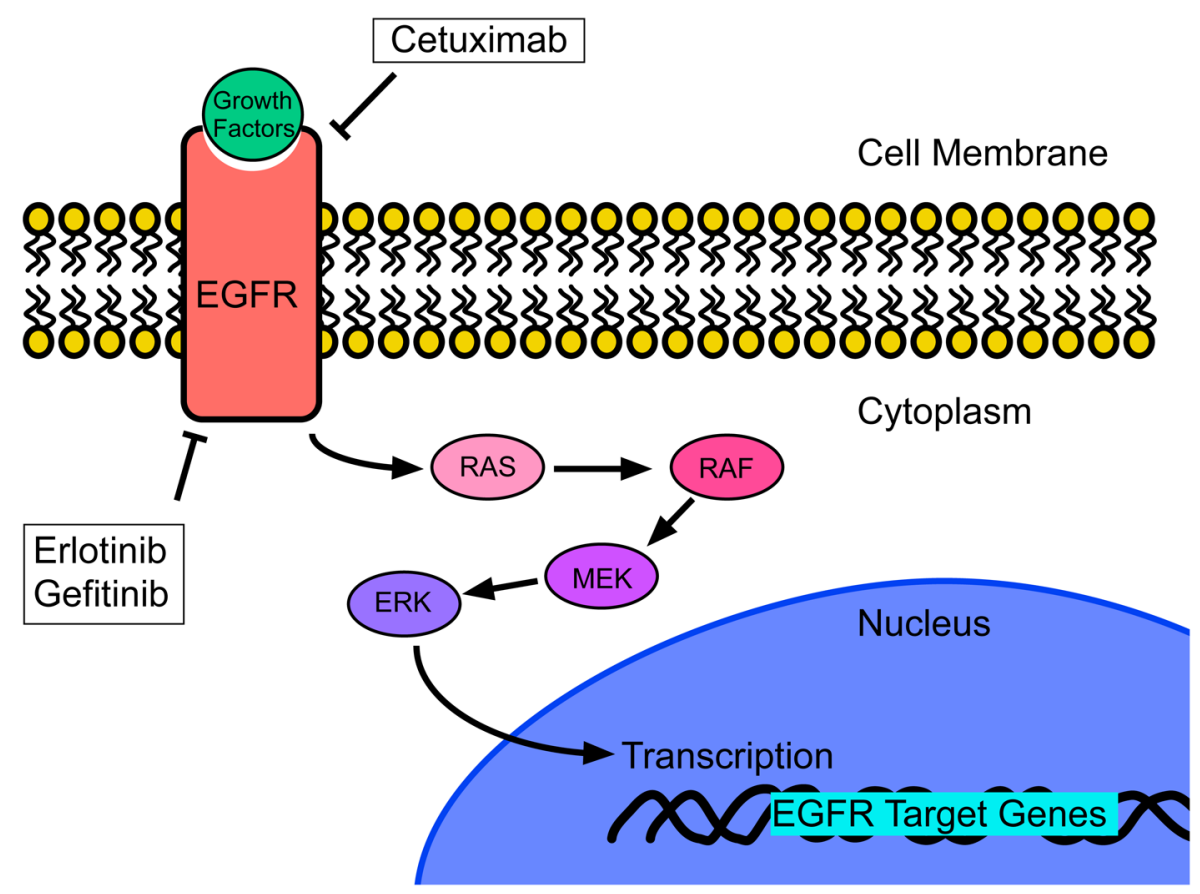

Figure 2.

Epidermal growth factor receptor (EGFR) pathway. EGFR is a receptor tyrosine kinase that, when bound to growth factor, causes downstream activation and phosphorylation of the protein kinase cascade and eventual transcription of EGFR target genes. Cetuximab, erlotinib, and gefitinib are examples of EGFR inhibitors that act specifically by inhibiting the receptor tyrosine kinase. 


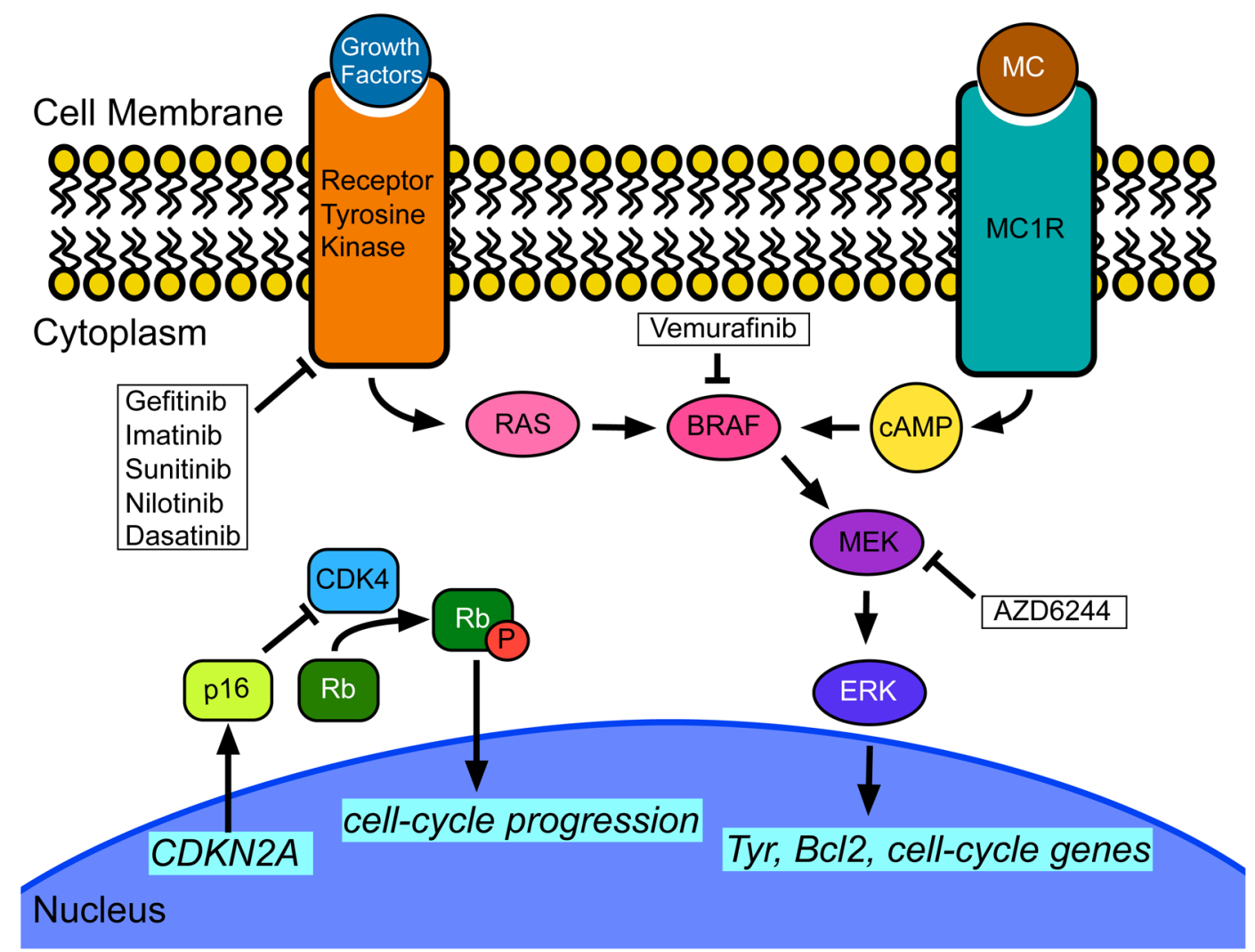

Figure 3.

Pathways in melanomagenesis. The receptor tyrosine kinase, when bound to a growth factor activates the ERK/MAP kinase pathway. The G-protein coupled receptor MC1R (melanocortin 1 receptor), when occupied by ligand melanocortin (MC) activates BRAF through cAMP. Oncogenic BRAF constitutively activates MEK and this results in a strong and sustained activation of ERK. The gene $C D K N 2 A$ encodes p16, which inhibits cyclindependent kinase 4 (CDK4). CDK4, when activated, leads to phosphorylation of the Retinoblastoma protein $(\mathrm{Rb})$ and subsequent cell-cycle progression. Loss of $C D K N 2 A$, therefore, leads to tumorigenesis through this pathway. So far, medications have been developed to inhibit the receptor tyrosine kinase itself as well as BRAF and MEK, directly. 